Check for updates

Cite this: RSC Adv., 2019, 9, 23614

Received 30th May 2019

Accepted 26th July 2019

DOI: 10.1039/c9ra04081a

rsc.li/rsc-advances

\section{An intramolecular relay catalysis strategy for Knoevenagel condensation and 1,3-dipolar cycloaddition domino reactions $\uparrow$}

\author{
Xiaofeng Yuan, ${ }^{a}$ Zijuan Wang, ${ }^{a}$ Qiang Zhang (DD ${ }^{\mathrm{b}}$ and Jun Luo (D) *a \\ A relay catalysis strategy was established by using a bifunctional catalyst which was prepared by \\ immobilization of organic chains containing secondary amine and $\mathrm{CU}(I)$ complex onto silica-coated \\ nano- $\mathrm{Fe}_{3} \mathrm{O}_{4}$. The simply prepared nanoparticles acted as efficient, intramolecular relays and magnetically \\ recyclable base-metal bifunctional catalysts for Knoevenagel condensation and 1,3-dipolar cycloaddition \\ domino reactions to prepare 5 -substituted $1 \mathrm{H}$-tetrazoles with excellent yields.
}

\section{Introduction}

Multifunctional catalysts for one-pot multistep reactions have attracted much attention recently owing to their high efficiency. ${ }^{\mathbf{1 - 1 2}}$ Bifunctional catalysts with different catalytic centers on separate or the same supports are the dominant targets in this field. ${ }^{13-33}$ For example, Shylesh et al. used organic amines and sulfonic acid bifunctionalized porous organosilicas in onepot deacetalization-nitroaldol cascade reactions. ${ }^{16}$ Shiju et al. prepared an efficient and robust bifunctional acid-base solid catalyst and evaluated the catalytic activities in deprotectionHenry domino reactions and deprotection-aldol reactions. ${ }^{17}$ Huang et al. prepared a bifunctional mesoporous silica nanoparticle with sulfonic acid moiety on its internal surface and organic amine moiety on its external surface and applied it in deacetalization-Henry cascade reactions. ${ }^{28}$ To sum up, the reported bifunctional supported catalysts were constructed by mainly two strategies: parallel immobilization of different catalytic moieties on the surface of the same support (Fig. 1(a)) or separate immobilization of different catalytic moieties on the internal and external surface respectively (Fig. 1(b)). The two design ideas are smart and attractive. However, for domino reactions, the mass transfer of intermediate products between two catalytic centers still needs time and energy. So, how can we make the transfer procedure more efficient? With this question in mind, we put forward a new strategy by sequentially connecting different catalytic moieties on the same organic chain and immobilizing it on the surface of one support (Fig. 1(c)).

${ }^{a}$ School of Chemical Engineering, Nanjing University of Science and Technology, Nanjing 210094, China.E-mail: luojun@njust.edu.cn

biangsu Key Laboratory of Environmental Functional Materials, School of Chemistry, Biology and Material Engineering, Suzhou University of Science and Technology, Suzhou 215009, China

$\dagger$ Electronic supplementary information (ESI) available. See DOI: 10.1039/c9ra04081a
Magnetic nanoparticles (MNPs) are attractive catalyst supports because they have advantages of excellent dispersion, easy separation and high compatibility with numerous kinds of catalysts. $^{34-42}$ Among them, silica coated MNPs attract increasing interests because they have a considerable amount of derivable hydroxyl groups and can be easily functionalized by catalyst-containing organosilicate esters. ${ }^{29,43-56}$ Our previous work speculated that the reactants would be adsorbed on the surface of the nano-support, so the local concentration of reactants around the catalytic sites would increase and then effectively elevate the reaction rate. ${ }^{48}$

The new relay catalysis using easily recyclable bifunctional nano-catalysts is illustrated in Fig. 2.

5-Substituted $1 H$-tetrazoles have extensive applications in chemistry. ${ }^{57-65}$ The conventional synthesis of these compounds is $[2+3]$ cycloaddition of nitriles with azide salts. ${ }^{66,67}$ A variety of catalysts for this transformation have been reported. ${ }^{68-81}$ However, the reported methods have one or more drawbacks such as use of highly toxic reagents, high cost, elevated reaction temperature, long reaction time or unsatisfactory recovery of catalyst. Therefore, the demand of efficient, economical and greener method for the preparation of 5 -substituted $1 \mathrm{H}$-tetrazoles is still demanded.

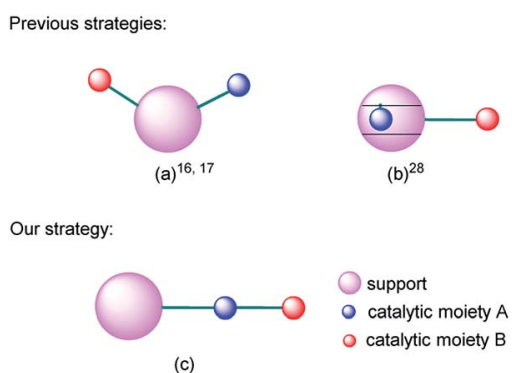

Fig. 1 Strategies of nanoparticle-supported bifunctional catalysts. 


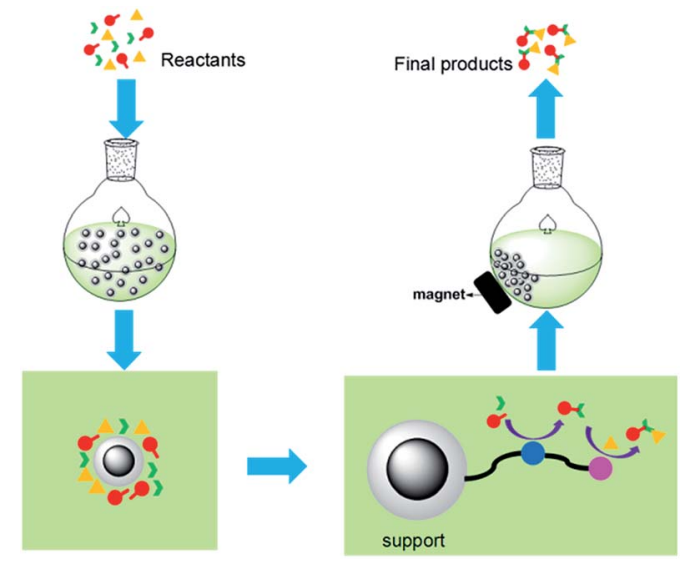

Fig. 2 Ideal relay catalysis for domino reactions.

Herein, we reported a new relay catalysis system involving the establishment of a secondary amine/Cu(II) bifunctional magnetic nanoparticle (NH-Cu(II)@MNP) characteristic of sequentially connecting secondary amine and copper(II) complex on the same organic chain, and application of it as efficient, intramolecular relay and magnetically recyclable bifunctional nano-catalyst in the one-pot synthesis of 5substituted $1 H$-tetrazoles through Knoevenagel condensation and 1,3-dipolar cycloaddition domino reactions.

\section{Results and discussion}

The procedure for the preparation of the nano- $\mathrm{Fe}_{3} \mathrm{O}_{4}$ supported secondary amine/ $\mathrm{Cu}$ (II) bifunctional catalyst (NH-Cu(II)@MNP) is shown in Scheme 1. The support $\mathrm{Fe}_{3} \mathrm{O}_{4} @ \mathrm{SiO}_{2}$ were prepared according to our previous work. ${ }^{48}$ Then [3-(2-aminoethyl)aminopropyl]triethoxysilane was introduced onto $\mathrm{Fe}_{3} \mathrm{O}_{4} @ \mathrm{SiO}_{2}$ through a condensation reaction. After that, the secondary amine functionalized precursor NH-L@MNP (2) was prepared by a condensation reaction of compound 1 with pyridine-2carbaldehyde. Meanwhile, the loading amount of the organic motif was determined to be $0.20 \mathrm{mmol} \mathrm{g}^{-1}$ by elemental analysis, which was also in accordance with thermogravimetric (TG) test. Ultimately, 2 was coordinated with $\mathrm{Cu}(\mathrm{OAc})_{2}$ in acetone at room temperature for $24 \mathrm{~h}$ to give the target catalyst 3 .

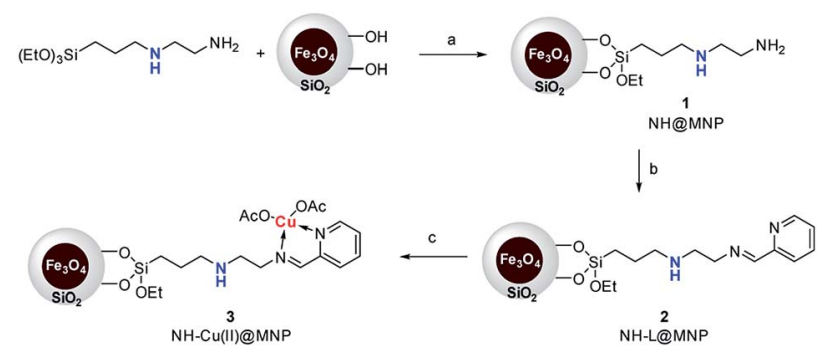

Scheme 1 Synthesis of MNP-supported bifunctional catalyst $\mathrm{NH}-$ $\mathrm{Cu}\left(\right.$ II) aMNP (3). Reaction conditions: (a) toluene, $\mathrm{N}_{2}$, reflux, $24 \mathrm{~h}$; (b) pyridine-2-carbaldehyde, EtOH, $\mathrm{N}_{2}$, reflux, $4 \mathrm{~h}$; (c) $\mathrm{Cu}(\mathrm{OAc})_{2} \cdot \mathrm{H}_{2} \mathrm{O}$, acetone, $\mathrm{N}_{2}, \mathrm{RT}, 24 \mathrm{~h}$.
The Fourier transform infrared (FT-IR) spectra of $\mathrm{Fe}_{3} \mathrm{O}_{4}$ @$\mathrm{SiO}_{2}$ and catalyst 3 are demonstrated in Fig. 3. The spectrum of $\mathrm{Fe}_{3} \mathrm{O}_{4} @ \mathrm{SiO}_{2}$ shows a moderate peak at $586 \mathrm{~cm}^{-1}$ ( $\mathrm{Fe}-\mathrm{O}$ vibration), a strong peak at $1087 \mathrm{~cm}^{-1}$ (Si-O-Si stretching vibration), a broad weak peak around $3263 \mathrm{~cm}^{-1}(\mathrm{O}-\mathrm{H}$ stretching vibration) and a weak peak at $1602 \mathrm{~cm}^{-1}$ (adsorbed water). All of these characteristic signals are observed in the spectrum of 3. Moreover, 3 shows typical bands at $1597 \mathrm{~cm}^{-1}(\mathrm{C}=\mathrm{N}$ vibration $)$ and $1446 \mathrm{~cm}^{-1}(\mathrm{C}=\mathrm{C}$ vibration of aryl ring). These results indicate that organic moiety was successfully immobilized onto $\mathrm{Fe}_{3} \mathrm{O}_{4} @ \mathrm{SiO}_{2}$.

Fig. 4 shows the X-ray diffraction (XRD) patterns of $\mathrm{Fe}_{3}$ $\mathrm{O}_{4} @ \mathrm{SiO}_{2}$ and 3. Both samples have the diffraction peaks on the standard $\mathrm{Fe}_{3} \mathrm{O}_{4}$ sample (Fig. 4(a), JCPDS file no. 19-0629). The broad peak of $2 \theta=20-30^{\circ}$ belongs to silica layer. The pattern of 3 (Fig. 4(b)) is similar to that of $\mathrm{Fe}_{3} \mathrm{O}_{4} @ \mathrm{SiO}_{2}$. But the intensity becomes weak in Fig. 4(b), indicating that the structure of $\mathrm{Fe}_{3} \mathrm{O}_{4} @ \mathrm{SiO}_{2}$ remains unchanged after being functionalized. The average crystal size of the $\mathrm{Fe}_{3} \mathrm{O}_{4}$ cores is about $11.4 \mathrm{~nm}$ according to the Scherrer formula.

The transmission electron microscope (TEM) images of $\mathrm{Fe}_{3} \mathrm{O}_{4} @ \mathrm{SiO}_{2}$ and 3 were recorded (Fig. 5). As shown in Fig. 5(a), the $\mathrm{Fe}_{3} \mathrm{O}_{4}$ cores are obviously surrounded by grey silica shells. The average size of the $\mathrm{Fe}_{3} \mathrm{O}_{4}$ cores and the support $\mathrm{Fe}_{3} \mathrm{O}_{4} @ \mathrm{SiO}_{2}$ are about 8-12 nm and $20 \mathrm{~nm}$, respectively. As shown in Fig. 5(b), the size of 3 is about $20-30 \mathrm{~nm}$. And after being reused six times, the morphology of recovered 3 does not show an obvious change (Fig. 5(c)).

The surface composition of $\mathbf{3}$ was analyzed with X-ray photoelectron spectroscopy (XPS). As shown in Fig. 6(a), the peaks with binding energy at 24.9, 102.2, 154.8, 284.9, 399.1, $531.7,933.1$ and $953.3 \mathrm{eV}$ were assigned to $\mathrm{O} 2 \mathrm{~s}$, Si 2p, Si 2s, C $1 \mathrm{~s}, \mathrm{~N} 1 \mathrm{~s}, \mathrm{O} 1 \mathrm{~s}, \mathrm{Cu} 2 \mathrm{p}_{3 / 2}$ and $\mathrm{Cu} 2 \mathrm{p}_{1 / 2}$, which affirmed that the catalyst was made up of $\mathrm{C}, \mathrm{O}, \mathrm{Si}, \mathrm{N}$ and $\mathrm{Cu}$. However, the peaks with binding energy at 711 and $723 \mathrm{eV}$ were distributed to $\mathrm{Fe}$ $2 \mathrm{p}_{3 / 2}$ and $\mathrm{Fe} 2 \mathrm{p}_{1 / 2}$, which indicated that there is a little $\mathrm{Fe}_{3} \mathrm{O}_{4}$ present on the surface of catalyst 3 . The intense and broad peaks at $932.8 \mathrm{eV}\left(\mathrm{Cu} 2 \mathrm{p}_{3 / 2}\right)$ and $952.5 \mathrm{eV}\left(\mathrm{Cu} 2 \mathrm{p}_{1 / 2}\right)$ along with the presence of the characteristic shakeup satellite peaks suggest that the copper on the surface has an oxidation state of +2 (Fig. 6(b)). ${ }^{82,83}$ Furthermore, in the $\mathrm{N}$ 1s spectrum of $3,-\mathrm{N}=$ $(398.7 \mathrm{eV})$ and $-\mathrm{NH}-(399.5 \mathrm{eV})$ were observed (Fig. 6(c)). ${ }^{84} \mathrm{In}$ a word, it is clear that the secondary amine and $\mathrm{Cu}(\mathrm{II})$ were

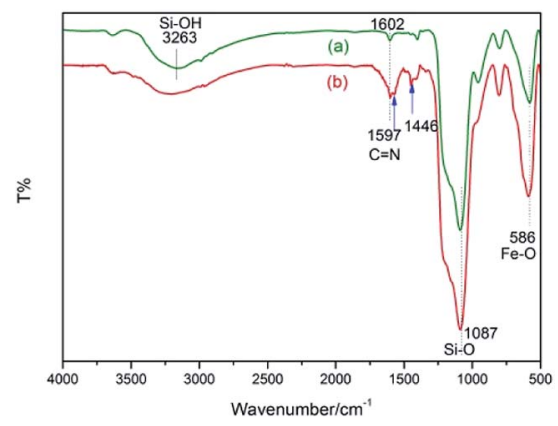

Fig. 3 FT-IR spectra of (a) $\mathrm{Fe}_{3} \mathrm{O}_{4} \mathrm{CSiO}_{2}$ and (b) $\mathrm{NH}-\mathrm{Cu}(\|) @ M N P$. 


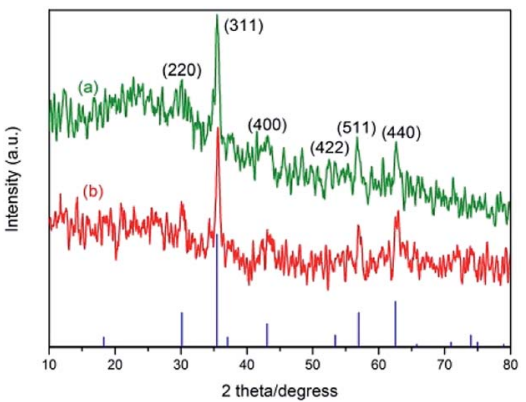

Fig. 4 XRD patterns of (a) $\mathrm{Fe}_{3} \mathrm{O}_{4} \mathrm{QSiO}_{2}$ and (b) $\mathrm{NH}-\mathrm{Cu}(\Perp) @ \mathrm{MNP}$ catalyst 3 .

successfully anchored on the surface of the $\mathrm{Fe}_{3} \mathrm{O}_{4} @ \mathrm{SiO}_{2}$ support.

Besides, the elemental mapping images (see ESI $\dagger$ ) also confirmed the existence of $\mathrm{Fe}, \mathrm{Si}, \mathrm{N}$ and $\mathrm{Cu}$, and these elements species were equably distributed on the NH-Cu(II)@MNP. Furthermore, the distribution density of nitrogen and copper was less than that of iron and silicon. This was in accordance with the load ratio of copper and nitrogen on $\mathrm{Fe}_{3} \mathrm{O}_{4} @ \mathrm{SiO}_{2}$ support.

The thermostability of $\mathbf{3}$ was investigated by thermogravimetric analysis (Fig. 7). The TG curve indicates an initial weight loss of $1.3 \%$ up to $100{ }^{\circ} \mathrm{C}$, which is ascribed to the adsorbed water. A main weight loss of $6.6 \%$ is observed from 350 to $620{ }^{\circ} \mathrm{C}$, which is attributed to the decomposition of organic structure. The peak in the derivative thermogravimetric (DTG) curve shows that the fastest loss of the organic moiety occurred at $480{ }^{\circ} \mathrm{C}$. Therefore, the thermostability of catalyst 3 is excellent.

The magnetic property was evaluated by vibrating sample magnetometer (VSM) test at room temperature (Fig. 8). The

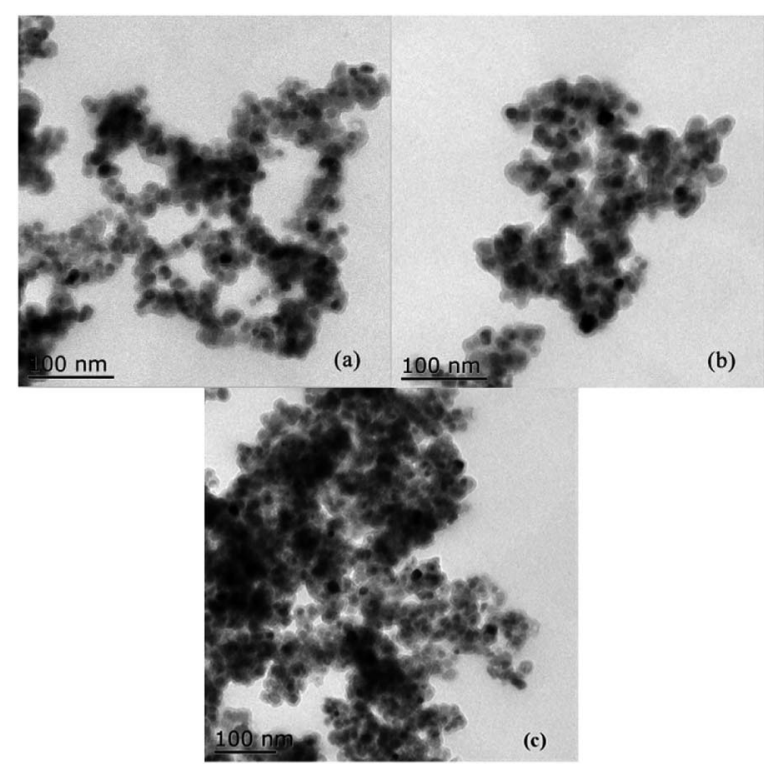

Fig. 5 TEM images of (a) $\mathrm{Fe}_{3} \mathrm{O}_{4}\left(\mathrm{aSiO}_{2}\right.$, (b) $\mathrm{NH}-\mathrm{Cu}(॥) @ M N P$ and (c) catalyst after being reused six times.
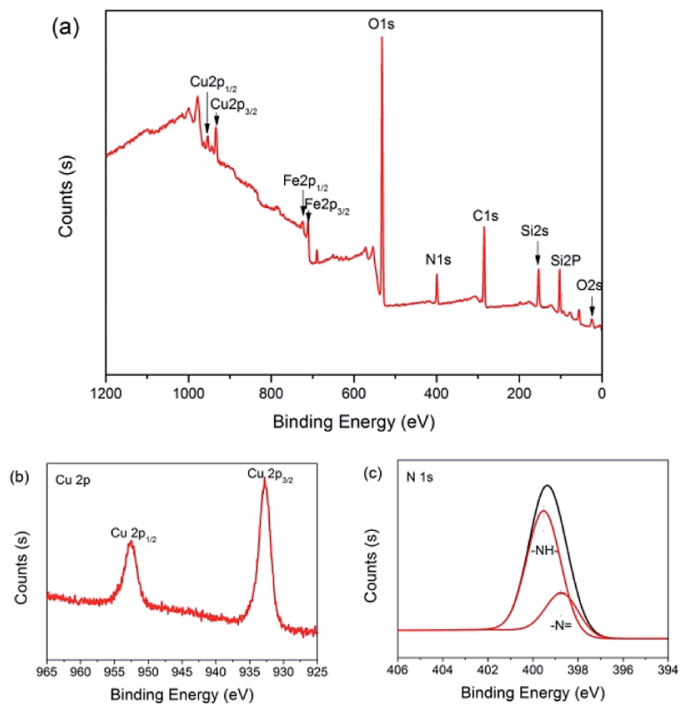

Fig. 6 The XPS spectra of the NH-Cu(I)@MNP catalyst 3. (a) Survey scan; (b) Cu 2p and (c) N 1s.

magnetization of samples could be completely saturated at high fields of up to $1.5 \mathrm{~T}$. And the maximum magnetic saturation intensity of 3 is $37.6 \mathrm{emu} \mathrm{g}^{-1}$ (Fig. 8(b)). The VSM magnetization curve of the sample goes through the zero point, so the catalyst has no magnetic hysteresis phenomenon, which indicates that the as-prepared catalyst is superparamagnetic.

The catalyst can be easily separated from the reaction system using an external magnet (Fig. 9).

The bifunctional catalytic performance of $\mathbf{3}$ was firstly investigated in a one-pot synthesis of $(E)-3-$ phenyl-2- $(1 H$ tetrazole-5-yl) acrylonitrile (6a) using benzaldehyde, malononitrile and sodium azide as the reactants. The domino reaction sequence was composed of two steps: Knoevenagel condensation and 1,3-dipolar cycloaddition. To clarify the bifunctional catalytic activity of 3 , the catalytic activities of a series of control samples were evaluated and the results are summarized in Table 1. For comparison, $\mathrm{Cu}(\mathrm{II}) @ \mathrm{MNP}$ (7), NH\|Cu(II)@MNP (8, parallel immobilization of $\mathrm{NH}$ and $\mathrm{Cu}(\mathrm{II})$ on the same support like Fig. 1(b)) and N-Cu(II) (9) were also prepared (see ESI $\dagger$ ).

The model Knoevenagel condensation of benzaldehyde (4a) and malononitrile at $80^{\circ} \mathrm{C}$ was conducted using NH-L@MNP (2)

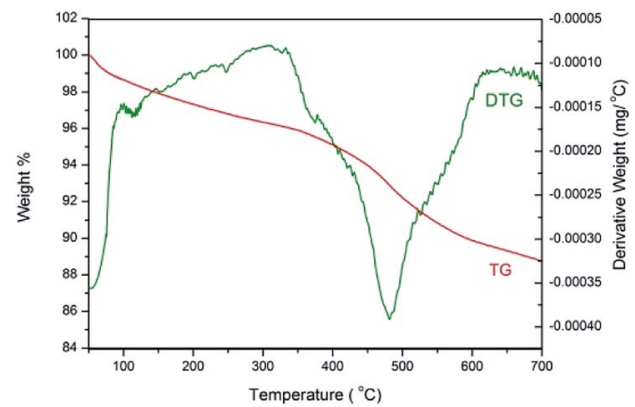

Fig. 7 Thermogravimetric (TG) and derivative thermogravimetric (DTG) curves for $\mathrm{NH}-\mathrm{Cu}(\Perp)$ aMNP. 


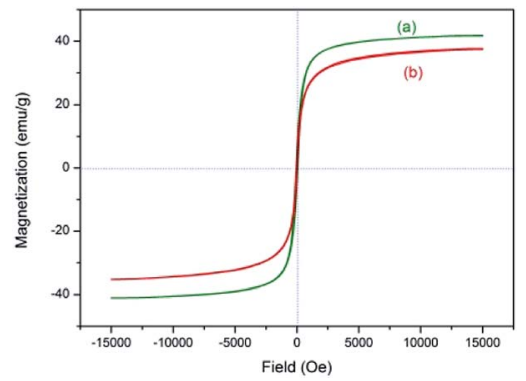

Fig. 8 VSM magnetization curve of (a) $\mathrm{Fe}_{3} \mathrm{O}_{4} \mathrm{aSiO}_{2}$ and (b) $\mathrm{NH}-\mathrm{Cu}(॥)$ aMNP.

and $\mathrm{NH}-\mathrm{Cu}(\mathrm{II}) @ \mathrm{MNP}$ (3) as catalysts. Both of them showed excellent activity while the latter was a little beat better (Table 1, entries 1-3). As for the control experiment without any catalyst, much longer time was required to get comparative yield (Table 1, entry 4). Meanwhile, the model 1,3-dipolar cycloaddition of $\mathbf{5 a}$ and sodium azide catalyzed by $\mathbf{3}$ gave excellent yield (Table 1 , entry 5). However, the control experiment using Cu(II)@MNP (7) as catalyst, longer reaction time was needed and lower yield was obtained (Table 1, entry 6). The domino reaction without any catalyst was conducted, both intermediate and final product were isolated but with low yields (Table 1, entry 7). Meanwhile, the support $\mathrm{Fe}_{3} \mathrm{O}_{4} @ \mathrm{SiO}_{2}$ and 2 had almost negligible effect on the yield of $6 \mathbf{a}$ (Table 1, entries 8 and 9). But the product ratio (6a: $5 \mathbf{a})$ of the reaction changed. In the case of 7 , the desired product was obtained with a much higher yield of $69 \%$ (Table 1 , entry 10). To our delight, the sequentially bifunctionalized catalyst 3 could efficiently catalyze the domino reaction and gave an excellent yield of $92 \%$ (Table 1 , entry 11). In comparison, when a mixture of the two monofunctionalized catalysts 2 and 7 were used, only $72 \%$ of $\mathbf{6 a}$ were obtained (Table 1, entry 12). Meanwhile, the parallelly bifunctionalized catalyst $\mathrm{NH} \| \mathrm{Cu}$ (II)@MNP (8) afforded obviously lower yield (80\%, Table 1 , entry 13), which was in accordance with our hypothesis. That is, the sequentially bifunctionalized catalyst 3 exhibited superb catalytic activity and selectivity than parallelly bifunctionalized analogue, the reason must be that the relay catalytic process is in favor of the mass transfer of intermediate product. To explore the effect of support, the catalytic performance of a homogeneous catalyst $\mathrm{N}-\mathrm{Cu}$ (II) (9) was tested, a significantly lower yield of $63 \%$ was obtained (Table 1, entry 15). The result showed that 9 displayed decreased catalytic efficiency. Moreover, we found

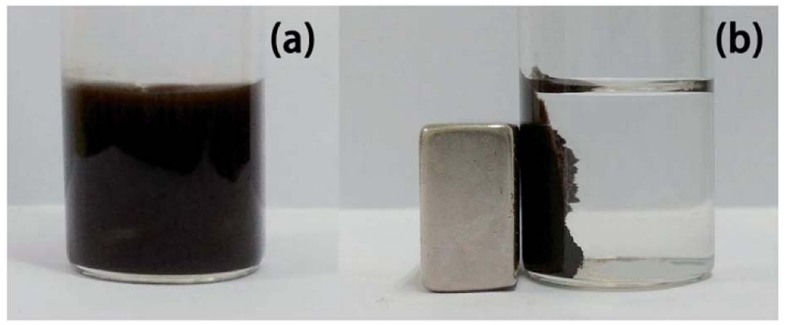

Fig. 9 A reaction mixture in the absence (a) or presence (b) of a magnetic field. that the physical mixture of $\mathrm{Cu}(\mathrm{OAc})_{2}$ and diethylamine exhibited lower catalytic activity too (Table 1, entry 14).

The domino reaction of benzaldehyde, malononitrile, sodium azide was investigated to find the optimal conditions (Table 2). The reaction without any catalyst afforded the product with low yield (Table 2, entry 1 ). Along with the increasing load of catalyst, the yield ascended accordingly (Table 2, entries 2 and 3). The best result was obtained by applying $20 \mathrm{mg}$ of 3 as catalyst and conducting the reaction at $80{ }^{\circ} \mathrm{C}$ (Table 2, entry 4 ). More catalyst demonstrated no significant effect on the yield (Table 2, entries 6 and 7). Prolonging the reaction time to $10 \mathrm{~h}$ resulted in almost unchanged yield (Table 2, entry 5). Lower reaction temperature was unfavourable to the reaction (Table 2 , entries 4, 8 and 9).

Thereafter, the above optimized reaction conditions were explored for the synthesis of a number of 5-substituted $1 \mathrm{H}$-tetrazoles. As shown in Table 3, a variety of aldehydes reacted smoothly with malononitrile and sodium azide to afford the

Table 1 The catalytic activity of various catalysts ${ }^{a}$

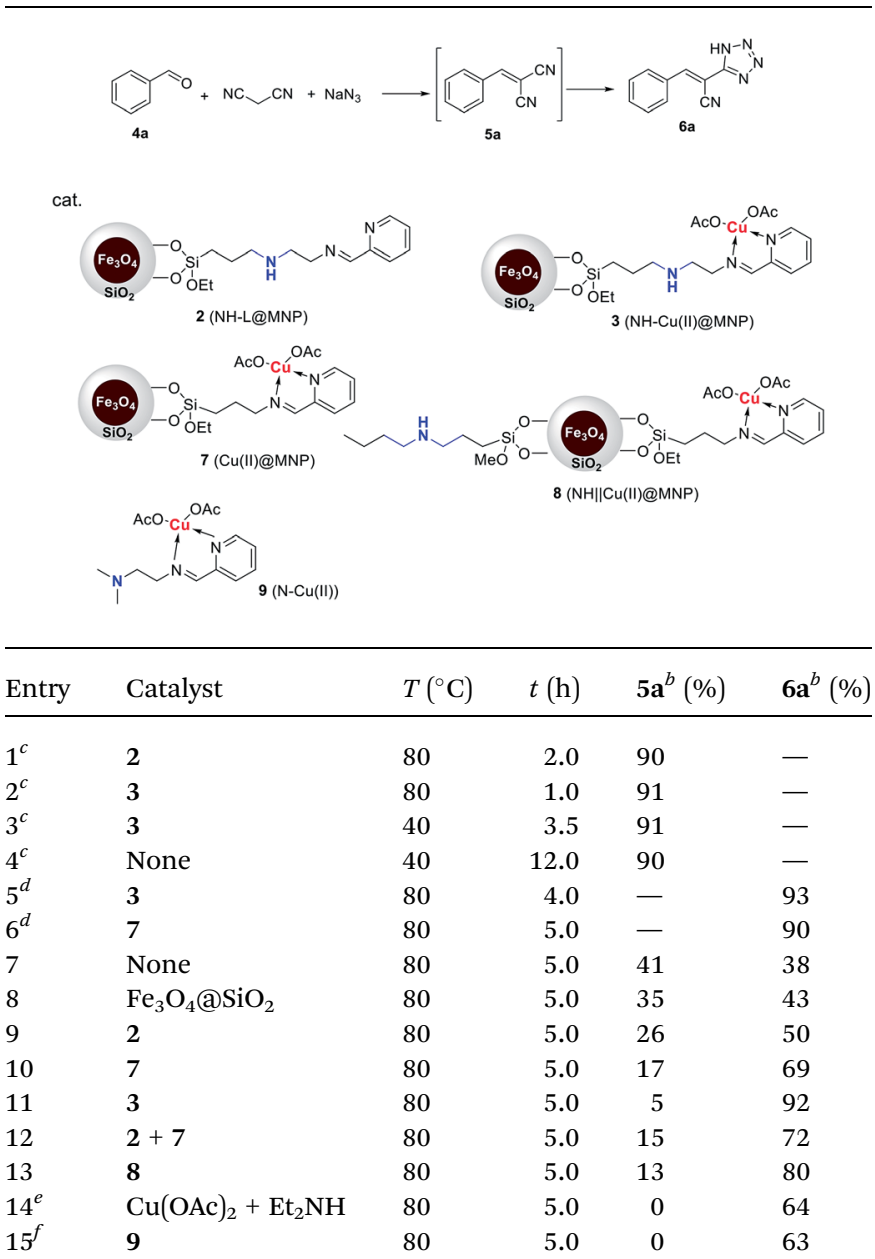

${ }^{a}$ Reaction conditions: benzaldehyde $(1.0 \mathrm{mmol})$, malononitrile (1.1 mmol), sodium azide $(1.2 \mathrm{mmol})$, catalyst $(1 \mathrm{~mol} \%, 20 \mathrm{mg})$, EtOH (10 $\mathrm{mL}), 80{ }^{\circ} \mathrm{C} .{ }^{b}$ Isolated yield. ${ }^{c}$ Only for the Knoevenagel condensation of benzaldehyde and malononitrile, i.e. in the absence of sodium azide. ${ }^{d}$ Only for the 1,3-dipolar cycloaddition of $\mathbf{5 a}$ and sodium azide. ${ }^{e} \mathrm{Cu}(\mathrm{OAc})_{2}(20 \mathrm{~mol} \%)$, diethylamine $(20 \mathrm{~mol} \%) .{ }^{f} \mathrm{~N}-\mathrm{Cu}(\mathrm{II})(1 \mathrm{~mol} \%)$. 
Table 2 Optimization of reaction conditions ${ }^{a}$

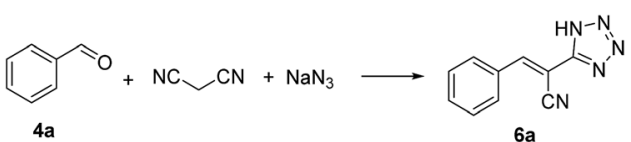

\begin{tabular}{lcccc}
\hline Entry & $3(\mathrm{mg})$ & $T\left({ }^{\circ} \mathrm{C}\right)$ & $t(\mathrm{~h})$ & Yield $^{b}(\%)$ \\
\hline 1 & 0 & 80 & 5 & 39 \\
2 & 5 & 80 & 5 & 66 \\
3 & 15 & 80 & 5 & 90 \\
4 & 20 & 80 & 5 & 92 \\
5 & 20 & 80 & 10 & 91 \\
6 & 50 & 80 & 5 & 91 \\
7 & 100 & 80 & 5 & 89 \\
8 & 20 & 50 & 5 & 75 \\
9 & 20 & 20 & 5 & 13
\end{tabular}

${ }^{a}$ Reaction conditions: benzaldehyde $(1.0 \mathrm{mmol})$, malononitrile (1.1 mmol), sodium azide $(1.2 \mathrm{mmol}), \mathrm{NH}-\mathrm{Cu}(\mathrm{II}) @ M N P$, EtOH $(10 \mathrm{~mL})$, 5 h. ${ }^{b}$ 6a (\%), isolated yield.

corresponding tetrazoles with excellent yields. meta-Methylbenzaldehyde (4c) resulted in a little higher yield than orthomethylbenzaldehyde (4b) and para-methylbenzaldehyde (4d). The aldehydes containing electron-withdrawing groups like bromo, chloro, iodo, fluoro and cyano in para positions (4e-i) produced more satisfactory yields than those containing electron-donating groups like ethyl, isopropyl, methoxy and tertbutyl in para positions $(\mathbf{4 j} \mathbf{j}-\mathbf{m})$. Heterocyclic aldehydes like thiophene-2-carbaldehydes (4n and 4o) also exhibited high reactivity and afforded the desired products with excellent yields. It is very strange that pyridine-2-carbaldehyde (4p) gave no desired product. When pyridine (1 equiv.) was added to the mixture of benzaldehyde, malonitrile, sodium azide and catalyst 3 , the yield of tetrazole was only $36 \%$. Based on this result, we supposed that the coordination of pyridine moiety and copper prevented the formation of the target product. From the above results, it is obvious that $\mathbf{3}$ is an efficient catalyst for the preparation of large spectrum of substituted tetrazoles with very high yields in ethanol.

A plausible mechanism is shown in Scheme 2. Initially, the substrates were absorbed on the surface of the catalyst by hydrogen bonds. Then active $\alpha-\mathrm{H}$ of malonitrile is abstracted by the secondary amine moiety (A) and the carbanion formed attacks the carbonyl, activated by acidic proton in ammonium, of benzaldehyde (B). After that, a synergistic dehydration occurs (C) to produce the intermediate product 2-benzylidenemalononitrile (5a). Subsequently, the coordination of the cyano group in 2-benzylidenemalononitrile with $\mathrm{Cu}(\mathrm{II})$ accompanying with anions exchange (replacement of acetate anion with azide) occurs (D), then a 1,3-dipolar cycloaddition between the $\mathrm{C} \equiv \mathrm{N}$ group and azide anion takes place readily to form the tetrazole ring (E). Another anions exchange occurs to afford the catalyst and sodium tetrazolate, gives target product by acidic workup.

One of the most significant features of a catalyst is its recyclability. Thus, the recyclability of $\mathbf{3}$ were tested in the model reaction under the optimized reaction conditions. The catalyst was separated from the reaction mixture by an external magnet

Table 3 The $\mathrm{NH}$-Cu(I) @MNP catalyzed one-pot synthesis of 5 -substituted $1 H$-tetrazoles ${ }^{a, b}$

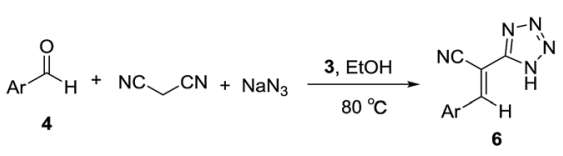

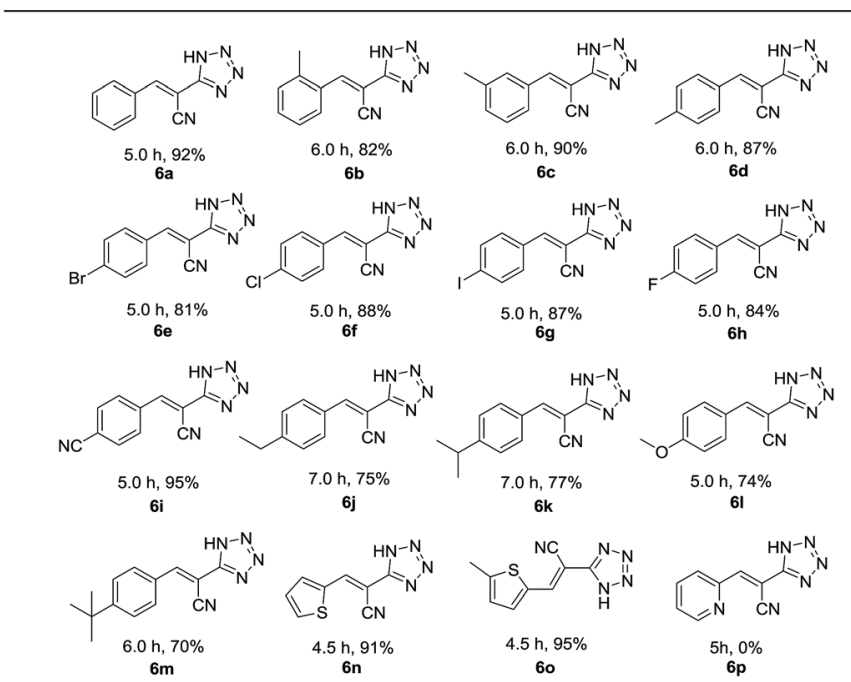

\footnotetext{
${ }^{a}$ Reaction conditions: aldehyde $(1.0 \mathrm{mmol})$, malononitrile $(1.1 \mathrm{mmol})$, sodium azide $(1.2 \mathrm{mmol})$, catalyst $3(20 \mathrm{mg}), \mathrm{EtOH}(10 \mathrm{~mL}), 80^{\circ} \mathrm{C} .{ }^{b}$ Isolated
} yield. 


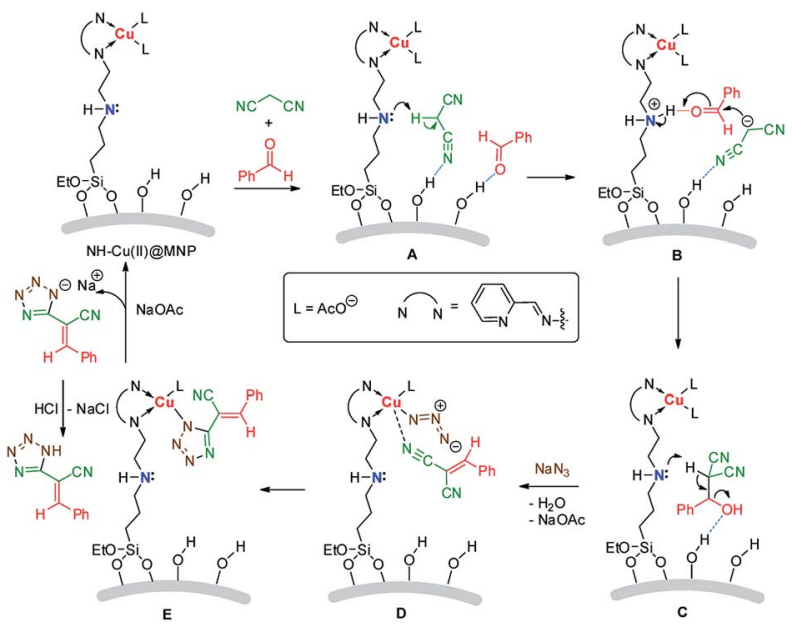

Scheme 2 Plausible reaction mechanism.

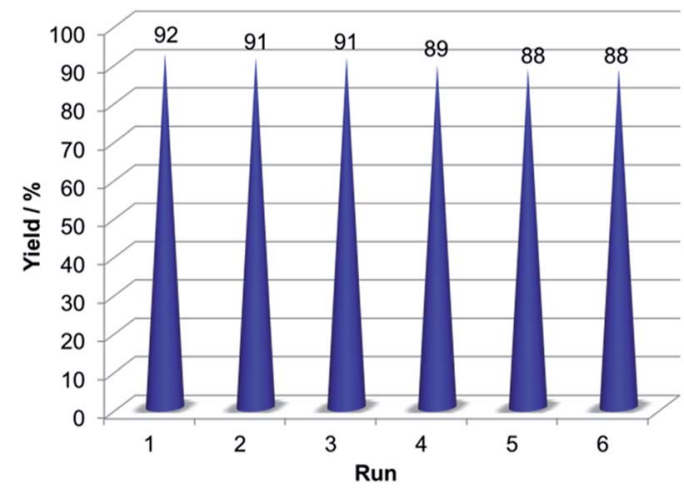

Fig. 10 Recycling experiment of the $\mathrm{NH}-\mathrm{Cu}(॥)$ @MNP.

and then washed with ethanol. Then the recovered catalyst was used in the next run. For all the six cycles, the catalyst could be reused without significant loss of catalytic activity (Fig. 10).

\section{Conclusions}

In summary, we have successfully established a relay catalysis strategy for one-pot domino reactions. A silica-coated nano$\mathrm{Fe}_{3} \mathrm{O}_{4}$-supported bifunctional amine/Cu(II) catalyst was prepared and used in the synthesis of 5-substituted $1 \mathrm{H}$-tetrazoles via a domino Knoevenagel condensation/1,3-dipolar cycloaddition pathway. Furthermore, the catalyst could be easily recovered from the reaction system by an external magnetic field and reused several times without loss of catalytic activity.

\section{Experimental section}

\section{Materials}

Toluene was dehydrated according to standard operation and stored on $4 \AA$ molecular sieves. Other solvents and all of the reagents were commercially available and were used without further purification. The core-shell $\mathrm{Fe}_{3} \mathrm{O}_{4} @ \mathrm{SiO}_{2}$ nanoparticles were prepared according to our previous work. ${ }^{48}$

\section{Synthesis of NH@MNP (1)}

$\mathrm{Fe}_{3} \mathrm{O}_{4} @ \mathrm{SiO}_{2}(1.0 \mathrm{~g})$ was dispersed in anhydrous toluene $(50 \mathrm{~mL})$ by sonication for $1 \mathrm{~h}$. [3-(2-Aminoethyl)aminopropyl]triethoxysilane $(0.529 \mathrm{~g}, 2.0 \mathrm{mmol})$ was then added, and the reaction mixture was refluxed for $24 \mathrm{~h}$ under nitrogen atmosphere. After being cooled to room temperature, $\mathbf{1}$ was recycled by a permanent magnet, washed with dry toluene and acetone to remove unreacted species and then dried under vacuum overnight.

\section{Synthesis of NH-L@MNP (2)}

$1(1.0 \mathrm{~g})$ was dispersed in anhydrous ethanol $(40 \mathrm{~mL})$ by sonication for $30 \mathrm{~min}$. Pyridine-2-carbaldehyde (0.214 g, $2.0 \mathrm{mmol})$ was then added, and the resulting mixture was stirred under reflux for $4 \mathrm{~h}$ under nitrogen atmosphere. Product 2 was recycled by a permanent magnet, washed with extra dry ethanol and then dried under vacuum overnight.

\section{Synthesis of NH-Cu(II)@MNP (3)}

Copper sulfate monohydrate $(0.399 \mathrm{~g}, 2.0 \mathrm{mmol})$ were dissolved in acetone $(40 \mathrm{~mL})$ and the solution was stirred at room temperature for $20 \mathrm{~min}$, then $2(1.0 \mathrm{~g})$ was added. The final mixture was stirred at room temperature for $24 \mathrm{~h}$ under nitrogen atmosphere. The catalyst $\mathbf{3}$ was collected by a permanent magnet, washed several times with acetone and dried under vacuum overnight. The loading content of $\mathrm{Cu}$ was $1.3 \%$ as determined by inductively coupled plasma atomic emission spectroscopy (ICP-AES).

\section{General procedure for the synthesis of tetrazoles 6}

A mixture of aldehyde $(1 \mathrm{mmol})$, malononitrile $(1.1 \mathrm{mmol})$, sodium azide $(1.2 \mathrm{mmol})$ and $3(20 \mathrm{mg}, 1.0 \mathrm{~mol} \%)$ in EtOH (10 $\mathrm{mL}$ ) was stirred at $80^{\circ} \mathrm{C}$ for set time. After completion of the reaction, as indicated by TLC, the reaction mixture was cooled to ambient temperature. The catalyst 3 was recovered by the same procedure mentioned above and used for the next run. To the reaction mixture was added $2 \mathrm{~N} \mathrm{HCl}(30 \mathrm{~mL})$ under vigorous stirring to precipitate the product. Then the mother liquor was extracted by ethyl acetate $(3 \times 50 \mathrm{~mL})$. The combined organic layers were dried over anhydrous $\mathrm{Na}_{2} \mathrm{SO}_{4}$ and evaporated under reduced pressure to obtain the crude product, the pure products were achieved by column chromatography on silica gel.

\section{Conflicts of interest}

There are no conflicts to declare.

\section{Acknowledgements}

This work was sponsored by the Natural Science Foundation of Jiangsu Province of China (no. BK2010485) and Qing Lan Project of Jiangsu Province, P. R. China (2014). 


\section{Notes and references}

1 Y. Yang, X. Liu, X. Li, J. Zhao, S. Bai, J. Liu and Q. Yang, Angew. Chem., Int. Ed., 2012, 51, 9164-9168.

2 P. Li, C. Y. Cao, Z. Chen, H. Liu, Y. Yu and W. G. Song, Chem. Commun., 2012, 48, 10541-10543.

3 A. V. Biradar, V. S. Patil, P. Chandra, D. S. Doke and T. Asefa, Chem. Commun., 2015, 51, 8496-8499.

4 Y. Z. Chen, Y. X. Zhou, H. Wang, J. Lu, T. Uchida, Q. Xu, S. H. Yu and H. L. Jiang, ACS Catal., 2015, 5, 2062-2069.

5 L. C. Lee, J. Lu, M. Weck and C. W. Jones, ACS Catal., 2016, 6, 784-787.

6 Z. Jia, K. Wang, B. Tan and Y. Gu, ACS Catal., 2017, 7, 36933702 .

7 U. Diaz, D. Brunel and A. Corma, Chem. Soc. Rev., 2013, 42, 4083-4097.

8 P. Zhao, Y. Zhang, Y. Wang, H. Cui, F. Song, X. Sun and L. Zhang, Green Chem., 2018, 20, 1551-1559.

9 P. Li, Y. Yu, H. Liu, C. Y. Cao and W. G. Song, Nanoscale, 2014, 6, 442-448.

10 Z. Miao, Y. Luan, C. Qi and D. Ramella, Dalton Trans., 2016, 45, 13917-13924.

11 H. Wang, Y. Wang, Y. Guo, X. K. Ren, L. Wu, L. Liu, Z. Shi and Y. Wang, Catal. Today, 2019, 330, 124-134.

12 B. Lai, F. Mei and Y. Gu, Chem.-Asian J., 2018, 13, 2529-2542.

13 B. Voit, Angew. Chem., Int. Ed., 2006, 45, 4238-4240.

14 K. Motokura, N. Fujita, K. Mori, T. Mizugaki, K. Ebitani and K. Kaneda, J. Am. Chem. Soc., 2005, 127, 9674-9675.

15 R. K. Zeidan, S. J. Hwang and M. E. Davis, Angew. Chem., Int. Ed., 2006, 45, 6332-6335.

16 S. Shylesh, A. Wagener, A. Seifert, S. Ernst and W. R. Thiel, Angew. Chem., Int. Ed., 2010, 49, 184-187.

17 N. R. Shiju, A. H. Alberts, S. Khalid, D. R. Brown and G. Rothenberg, Angew. Chem., Int. Ed., 2011, 50, 9615-9619.

18 K. Motokura, M. Tada and Y. Iwasawa, J. Am. Chem. Soc., 2009, 131, 7944-7945.

19 F. Shang, J. Sun, H. Liu, C. Wang, J. Guan and Q. Kan, Mater. Res. Bull., 2012, 47, 801-806.

20 F. Shang, J. Sun, S. Wu, Y. Yang, Q. Kan and J. Guan, Microporous Mesoporous Mater., 2010, 134, 44-50.

21 E. Merino, E. Verde-Sesto, E. M. Maya, M. Iglesias, F. Sánchez and A. Corma, Chem. Mater., 2013, 25, 981-988.

22 Y. Zhang, B. Li and S. Ma, Chem. Commun., 2014, 50, 85078510.

23 B. Li, Y. Zhang, D. Ma, L. Li, G. Li, G. Li, Z. Shi and S. Feng, Chem. Commun., 2012, 48, 6151-6153.

24 F. Zhang, H. Jiang, X. Li, X. Wu and H. Li, ACS Catal., 2014, 4, 394-401.

25 F. Zhang, H. Jiang, X. Wu, Z. Mao and H. Li, ACS Appl. Mater. Interfaces, 2015, 7, 1669-1677.

26 S. Shylesh, A. Wagner, A. Seifert, S. Ernst and W. R. Thiel, Chem.-Eur. J., 2009, 15, 7052-7062.

27 J. Gao, X. Zhang, Y. Lu, S. Liu and J. Liu, Chem.-Eur. J., 2015, 21, 7403-7407.

28 Y. Huang, S. Xu and V. S. Lin, Angew. Chem., Int. Ed., 2011, 50, 661-664.
29 L. Liu, Y. Ai, D. Li, L. Qi, J. Zhou, Z. Tang, Z. Shao, Q. Liang and H. B. Sun, ChemCatChem, 2017, 9, 3131-3137.

30 Z. Weng, T. Yu and F. Zaera, ACS Catal., 2018, 8, 2870-2879.

31 R. Kardooni and A. R. Kiasat, J. Taiwan Inst. Chem. Eng., 2018, 87, 241-251.

32 P. Chandra, A. M. Jonas and A. E. Fernandes, ACS Catal., 2018, 8, 6006-6011.

33 L. Xiong, H. Zhang, Z. He, T. Wang, Y. Xu, M. Zhou and K. Huang, New J. Chem., 2018, 42, 1368-1372.

34 S. Shylesh, V. Schunemann and W. R. Thiel, Angew. Chem., Int. Ed., 2010, 49, 3428-3459.

35 S. Yang, C. Cao, Y. Sun, P. Huang, F. Wei and W. Song, Angew. Chem., Int. Ed., 2015, 54, 2661-2664.

36 Z. S. Wu, S. Yang, Y. Sun, K. Parvez, X. Feng and K. Mullen, J. Am. Chem. Soc., 2012, 134, 9082-9085.

37 J. Dai, H. Zou, R. Wang, Y. Wang, Z. Shi and S. Qiu, Green Chem., 2017, 19, 1336-1344.

38 A. Mohammadinezhad and B. Akhlaghinia, Green Chem., 2017, 19, 5625-5641.

39 W. Gu, X. Deng, X. Jia, J. Li and E. Wang, J. Mater. Chem. A, 2015, 3, 8793-8799.

40 R. B. Baig and R. S. Varma, Chem. Commun., 2013, 49, 752770.

41 Q. Deng, Y. Shen, H. Zhu and T. Tu, Chem. Commun., 2017, 53, 13063-13066.

42 V. Polshettiwar, R. Luque, A. Fihri, H. Zhu, M. Bouhrara and J. M. Basset, Chem. Rev., 2011, 111, 3036-3075.

43 M. J. Jin and D. H. Lee, Angew. Chem., Int. Ed., 2010, 49, 11191122.

44 Q. Yue, J. Li, Y. Zhang, X. Cheng, X. Chen, P. Pan, J. Su, A. A. Elzatahry, A. Alghamdi, Y. Deng and D. Zhao, J. Am. Chem. Soc., 2017, 139, 15486-15493.

45 I. Elsayed, M. Mashaly, F. Eltaweel, M. A. Jackson and E. B. Hassan, Fuel, 2018, 221, 407-416.

46 N. Azgomi and M. Mokhtary, J. Mol. Catal. A: Chem., 2015, 398, 58-64.

47 R. Gupta, M. Yadav, R. Gaur, G. Arora and R. K. Sharma, Green Chem., 2017, 19, 3801-3812.

48 Q. Zhang, H. Su, J. Luo and Y. Wei, Green Chem., 2012, 14, 201-208.

49 Q. Zhang, H. Su, J. Luo and Y. Wei, Catal. Sci. Technol., 2013, 3, 235-243.

50 S. Wang, Z. Zhang, B. Liu and J. Li, Catal. Sci. Technol., 2013, 3, 2104-2112.

51 N. Mir, A. Heidari, H. Beyzaei, S. Mirkazehi-Rigi and P. Karimi, Chem. Eng. J., 2017, 327, 648-655.

52 Q. Zhou, Z. Wan, X. Yuan and J. Luo, Appl. Organomet. Chem., 2016, 30, 215-220.

53 S. Wang, J. Tang, H. Zhao, J. Wan and K. Chen, J. Colloid Interface Sci., 2014, 432, 43-46.

54 J. Zhou, Y. Li, H.-b. Sun, Z. Tang, L. Qi, L. Liu, Y. Ai, S. Li, Z. Shao and Q. Liang, Green Chem., 2017, 19, 3400-3407.

55 Y. Ai, Z. Hu, Z. Shao, L. Qi, L. Liu, J. Zhou, H. Sun and Q. Liang, Nano Res., 2018, 11, 287-299.

56 T. Zeng, L. Yang, R. Hudson, G. Song, A. R. Moores and C. J. Li, Org. Lett., 2011, 13, 442-445. 
57 V. Rama, K. Kanagaraj and K. Pitchumani, J. Org. Chem., 2011, 76, 9090-9095.

58 M. Zarghani and B. Akhlaghinia, $R S C A d v ., 2016,6,31850-$ 31860.

59 M. Massi, S. Stagni and M. I. Ogden, Coord. Chem. Rev., 2018, 375, 164-172.

60 T. A. Kuz'menko, A. S. Morkovnik, L. N. Divaeva, G. S. Borodkin and V. V. Kuz'menko, Chem. Heterocycl. Compd., 2015, 50, 1575-1585.

61 D. C. Zhong, Y. Q. Wen, J. H. Deng, X. Z. Luo, Y. N. Gong and T. B. Lu, Angew. Chem., Int. Ed., 2015, 54, 11795-11799.

62 S. Khaghaninejad, M. M. Heravi, T. Hosseinnejad, H. A. Oskooie and M. Bakavoli, Res. Chem. Intermed., 2016, 42, 1593-1610.

63 R. P. Singh, R. D. Verma, D. T. Meshri and J. M. Shreeve, Angew. Chem., Int. Ed., 2006, 45, 3584-3601.

64 A. L. Chandgude and A. Domling, Green Chem., 2016, 18, 3718-3721.

65 Z. N. Tisseh, M. Dabiri, M. Nobahar, H. R. Khavasi and A. Bazgir, Tetrahedron, 2012, 68, 1769-1773.

66 F. Himo, Z. P. Demko, L. Noodleman and K. B. Sharpless, J. Am. Chem. Soc., 2002, 124, 12210-12216.

67 F. Himo, Z. P. Demko, L. Noodleman and K. B. Sharpless, J. Am. Chem. Soc., 2003, 125, 9983-9987.

68 D. Habibi, M. Nasrollahzadeh and Y. Bayat, Synth. Commun., 2011, 41, 2135-2145.

69 S. Kumar, S. Dubey, N. Saxena and S. K. Awasthi, Tetrahedron Lett., 2014, 55, 6034-6038.

70 D. Kong, Y. Liu, J. Zhang, H. Li, X. Wang, G. Liu, B. Li and Z. Xu, New J. Chem., 2014, 38, 3078-3083.
71 D. R. Patil, Y. B. Wagh, P. G. Ingole, K. Singh and D. S. Dalal, New J. Chem., 2013, 37, 3261-3266.

72 P. Mani, A. K. Singh and S. K. Awasthi, Tetrahedron Lett., 2014, 55, 1879-1882.

73 F. Dehghani, A. R. Sardarian and M. Esmaeilpour, J. Organomet. Chem., 2013, 743, 87-96.

74 M. Abdollahi-Alibeik and A. Moaddeli, New J. Chem., 2015, 39, 2116-2122.

75 M. Esmaeilpour, J. Javidi and S. Zahmatkesh, Appl. Organomet. Chem., 2016, 30, 897-904.

76 M. Esmaeilpour, J. Javidi, F. Nowroozi Dodeji and M. Mokhtari Abarghoui, J. Mol. Catal. A: Chem., 2014, 393, 18-29.

77 M. Khanmoradi, M. Nikoorazm and A. GhorbaniChoghamarani, Appl. Organomet. Chem., 2017, 31, e3693.

78 M. Abdollahi-Alibeik and A. Moaddeli, J. Chem. Sci., 2016, 128, 93-99.

79 F. Taghavi, M. Gholizadeh, A. S. Saljooghi and M. Ramezani, MedChemComm, 2017, 8, 1953-1964.

80 A. Ghorbani-Choghamarani, L. Shiri and G. Azadi, RSC Adv., 2016, 6, 32653-32660.

81 G. Azadi, A. Ghorbani-Choghamarani and L. Shiri, Transition Met. Chem., 2017, 42, 131-136.

82 L. Liao, Y. Liu, Z. Li, J. Zhuang, Y. Zhou and S. Chen, RSC Adv., 2016, 6, 94976-94988.

83 L. Chen, B. Li and D. Liu, Catal. Lett., 2014, 144, 1053-1061. 84 B. Huang, Y. Liu, B. Li, S. Liu, G. Zeng, Z. Zeng, X. Wang, Q. Ning, B. Zheng and C. Yang, Carbohydr. Polym., 2017, 157, 576-585. 